\title{
HISTORIA TEXTUAL DE LA \\ NUEVA TOPOGRAFÍA DE ARGEL DE ALONSO CANO
}

ISAAC DONOSO

Universidad de Alicante

Alonso CAno, La Regencia de Argel en el siglo XVIII. Nuevo aspecto, topografía de la ciudad y su Estado, sus fuerzas y su gobierno actual computado con el antiguo, manuscrito presentado, traducido y transcrito por Ismet Terki-Hassaine, Orán, Dār al-Qūds, 2010, 176 pp. [9789947-927-31-1]

Alonso CANO, La Regence d'Alger au XVIIIe siècle. Nouvel aspect topographique de la ville son Etat ses forces et son gouvernement actuel comparé avec l'ancien, manuscrit présenté et traduit de l'espagnol par Ismet Terki-Hassaine, Orán, Dār al-Qūds, 2010, 196 pp. [978-9947927-30-4]

José Miguel Escribano y RicARDo CASTILlO LARRIBA, Argel Delenda Est. El "Nuevo Aspecto de la Topografía de la Ciudad y Regencia de Argel" de Fray Alonso Cano y Nieto, Archivo de la Frontera, 2010, $134 \mathrm{pp}$.

[http://www.archivodelafrontera.com/wp-content/uploads/2010/03/GFUENTES-02.pdf]

EMILIO SOLA, La redención de cautivos de 1769 y la nueva topografía de Argel de Alonso Cano de 1770. Versión versiculada del documento Argel Delenda Est. El "Nuevo Aspecto de la Topografía de la Ciudad y Regencia de Argel' de Fray Alonso Cano, Archivo de la Frontera, 2010, $164 \mathrm{pp}$.

[http://www.archivodelafrontera.com/wp-content/uploads/2010/03/GFUENTES-02versiculada.pdf]

Fr. Alonso Cano y Nieto, Nueva topografía de Argel, edición de Mireia Llopis Susierra, composición y diseño de Ana Enmicucx y estudio y notas de Andrés Díaz Borrás, Valencia, Gallo de Fuego, 2014, 264 pp. [978-84-943089-0-1] 
En los últimos años han aparecido numerosas publicaciones, electrónicas, monográficas, versiculadas y traducciones, que tenían por objeto la edición de un texto, hasta entonces inédito, de singular valor. El texto había sobrevivido en diferentes manuscritos, al menos cinco, en apariencia copias desde una redacción original de 1770. La obra tenía su origen en la empresa regia de Carlos III para la redención general de cautivos en Argel, desde el 9 de octubre de 1768 a febrero de 1769, encargada a fray Alonso Cano Nieto, trinitario calzado, fray Antonio Manuel de Cantalejo, de la Real y Militar Orden de la Merced, y fray Juan de la Virgen, trinitario descalzo ${ }^{1}$. Tras cinco meses de presencia en la Regencia otomana de Argel, los redentores enviados por el monarca español consiguieron rescatar a centenares de cautivos cristianos, a cambio de miles de pesos y bastantes "moros de canje". En la operación se rescataron los tabarquinos que habían sido apresados por el bey de Túnez en 1741, y que permanecían retenidos y esclavizados en la Regencia:

En Argel los padres redentores han ido reuniendo al grupo de tabarquinos, así el diecinueve de diciembre de 1768 han agrupado un total de doscientas cuarenta personas de toda edad y estado que se encontraban distribuidas entres Constantina, Moscava y Tenez teniendo que pagar a razón de seiscientos pesos de plata. Ya que a causa del temporal los barcos de la marina española hubieron de volver antes de lo previsto, trayendo por un lado parte de los moros que se querían canjear y por otro, teniendo el conocimiento de la existencia del grupo tabarquino, los padres redentores eran conscientes de que debía intentarse actuar con la máxima rapidez para obtener un resultado positivo ${ }^{2}$.

Este contingente de población de origen ligur y vínculos con la República de Génova dio forma a la ciudad de Nueva Tabarca en la isla Plana de Santa Pola, en las costas alicantinas, ciudad creada de nueva planta por Carlos III. Al tiempo que se permitía continuar la vida marinera de esta población mediterránea, se defendía la costa de Alicante

1 "Redempzion General Que de Orden de S. M. que (Dios Guarde) se hà executado en la Ciudad de Argel, en Los Años de 1768. y 1769. por Las tres Religiones Trinidad Calzada, Merced Calzada, y Trinidad Descalza", Archivo Histórico Nacional, Madrid, 1768-69: [ES.28079.AHN/5.1.3//CODICES,L.150]. 106.

${ }^{2}$ José Luis González Arpide, Los tabarquinos, Alicante, Instituto Juan Gil-Albert, 2002, p. 
con gente escarmentada y experta en las operaciones del corso norteafricano ${ }^{3}$.

Los meses pasados en la ciudad de Argel no fueron desaprovechados por el trinitario calzado fray Alonso Cano Nieto, conquense nacido en Mota del Cuervo en 1711, para emular a Diego de Haedo y realizar una relación exhaustiva e historia general de la república norteafricana, objeto de deseo eterno para la monarquía hispánica. De este modo recaba datos de forma clandestina y observa el funcionamiento de la Regencia para componer su Nuevo aspecto de la Topografía de la Ciudad y Regencia de Argel. Su Estado, fuerzas y gobierno actual, computado con el antiguo, obra que queda manuscrita en 1770. El texto, dividido en tres libros y un apéndice, describe la topografía y las defensas militares de Argel, su estructura administrativa, y los derechos de España a los territorios argelinos. La idea última de la obra es legitimar la soberanía histórica de la monarquía hispánica sobre la plaza de Argel, como así manifestaba el control sobre la ciudad de Orán. Alonso Cano exhortaba a continuar el proyecto frustrado de conquista del norte africano, y parecía delinear un plan entusiasta sobre la facilidad de conquistar "el nido de piratas".

Lo cierto es que informes y relaciones debieron de llegar a la corte, y se organizó rápidamente un proyecto de conquista de Argel, encomendado al irlandés Alejandro O’Reilly. En julio de 1775 la armada española desembarcó en las proximidades de la medina argelina, en una batalla cruenta que causó miles de bajas en el bando español, antes de que la escuadra huyera en retirada hacia Alicante. Sin duda este lamentable acontecimiento, el último de los intentos españoles por conquistar Argel, sentenció definitivamente la fortuna editorial del manuscrito de Alonso Cano, que nunca vio la luz, al tiempo que cedía el futuro de la Regencia a otras potencias coloniales ${ }^{4}$.

\footnotetext{
${ }^{3}$ Puede verse edición parcial de la relación del rescate, Relación puntual de los acaecimientos ocurridos en la comisión del canje y rescate de cristianos cautivos de Argel y transporte de moros que se puso al cargo del capitán de navio don José Díaz de Veañes con el mando de la escuadra de los navios de Su Majestad nombrados San Isidro, Santa Isabel, San Vicente y fragata Santa Teresa, desde la salida del puerto de Cartagena hasta el arribo al de Mallorca, en José Luis González Arpide, "La expedición de Argel y el rescate de los tabarquinos”, en María Antonia Morán Suárez y María del Carmen Rodríguez López (coords.), La documentación para la investigación: homenaje a José Antonio Martín Fuertes, León, Universidad de León, 2002, vol. 1, pp. 255-276.

${ }^{4}$ Véase Frank Lambert, The Barbary Wars: American Independence in the Atlantic World, Nueva York, Hill \& Wang, 2005.
} 
Las nuevas tecnologías permiten hoy en día que el acceso sea inmediato a los manuscritos existentes, al menos tres, cuyo texto completo se encuentra digitalizado y de libre acceso a través de la red $^{5}$. Este acceso inmediato explica en parte que, ahora sí, el texto haya recibido la atención que los siglos le habían negado, y en los últimos años se haya producido una vertiginosa actividad por restituir la obra del trinitario como pieza importante dentro de la historiografía sobre Argel. Habría que destacar en primer lugar los dos volúmenes de Ismet Terki-Hassaine, uno en español (con tapa gris) y otro en francés (con tapa dorada), editando y traduciendo al francés respectivamente el texto del manuscrito Gayangos, con un valioso estudio introductorio de veinte páginas, donde reivindica el valor de las fuentes españolas para la historia de Argelia. Ciertamente esta empresa representa una contribución significativa, no sólo a la historiografía y el hispanismo argelino, sino sobre todo, a la producción en lengua española por parte de autores argelinos y la aparición de libros en español en Argelia, un fenómeno escaso, pero no anecdótico, que pone de manifiesto la tradición argelina con la lengua de Cervantes. Insistimos, creemos que es un verdadero regalo poder ir a librerías de Orán o Argel y encontrar en la sección de actualidad libros argelinos publicados en lengua española. Y como regalo entendemos los libros de Terki-Hassaine, un esfuerzo filológico laudable que disculpa la complejidad de la empresa y los rigores que toda edición sufre.

Desde el manuscrito conservado en la Universidad de Alcalá - copia de 1778- se realiza la siguiente edición completa del texto, labor de José Miguel Escribano y Ricardo Castillo. El resultado aparece de forma electrónica en el portal «Archivo de la frontera», iniciativa de la misma universidad que inició su andadura en 1999 y que posee, en el momento

\footnotetext{
5 Nuevo aspecto de la topografía de Árgel [manuscrito]: su estado, fuerzas y govierno actual comparado con el antiguo / Su author el M.R.P.M. fray Alonso Cano, trinitario calzado y actualmente obispo de Segorbe, año de 1770. Manuscrito digitalizado de la Real Academia de la Historia: [http://bibliotecadigital.rah.es/dgbrah/es/consulta/registro.cmd?id=5982]; Nuebo aspecto de la topografía de la ciudad y regencia de Argel : su estado, fuerzas, y govierno actual, computado con el antiguo / su author el M.R.P.M.F. Alonso Cáno, trinitario calzado, y actualmente obispo de Segorve, año de 1770; trasladado aqui desde su manoescrito original, año de 1778. Manuscrito de la Universidad de Alcalá de Henares: [http://dspace.uah.es/dspace/handle/10017/7233]; Nuevo aspecto de la topografía de la ciudad y regencia de Argel : su estado, fuerzas y gobierno actual, computado con el antiguo su autor Fr. Alonso Cano, Trinitario calzado y, actualmente, Obispo de Segorbe. Manuscrito de la Colección Gayangos de la Biblioteca Nacional:

[http://bdh.bne.es/bnesearch/detalle/bdh0000010991].
} 
presente, un ingente repositorio de textos, ediciones y estudios originales, una verdadera biblioteca que ofrece material de elaboración propia sobre múltiples temas, entre ellos el Mediterráneo otomano. El estudio de Escribano y Castillo relaciona por primera vez la lista de manuscritos existentes (pp. 11-12), las fuentes de la obra, y recupera un retrato de Alonso Cano conservado en la catedral de Segorbe, de la cual fue obispo desde 1770 hasta su muerte en 1780. Desde este texto el siempre sorprendente Emilio Sola realiza una magnífica versión versiculada, en verso, entendiendo agudamente la estructura interna del texto del trinitario, como obra perfectamente manufacturada dentro de los patrones de la retórica ilustrada, y del docere et delectare. No se quedan aquí las ediciones del texto sino que en 2014 aparece en Valencia otra empresa de recuperación textual de la Nueva topografía de Argel, a varias manos, edición de Mireia Llopis, composición y diseño de Ana Enmicucx, y estudio y notas de Andrés Díaz Borrás.

En fin, Alonso Cano aprovechó el privilegio de estar unos meses en la Argel de mediados del siglo XVIII para redactar un texto que emulase la histórica topografía de Haedo y, como 'nuevo aspecto', culminase la empresa de anexión militar a la par que ruina del corso. El corsarismo argelino se arruinó, pero también lo hicieron los sueños españoles de conquistar Argel, beneficiándose de todo ello potencias emergentes ante el vacío de poder de los reinos que habían gobernado el Mediterráneo, España y el Imperio otomano. La Nueva topografía de Argel acabó formando parte del mundo antiguo; serían ya los franceses quienes con ahínco delineasen los mapas norteafricanos. 


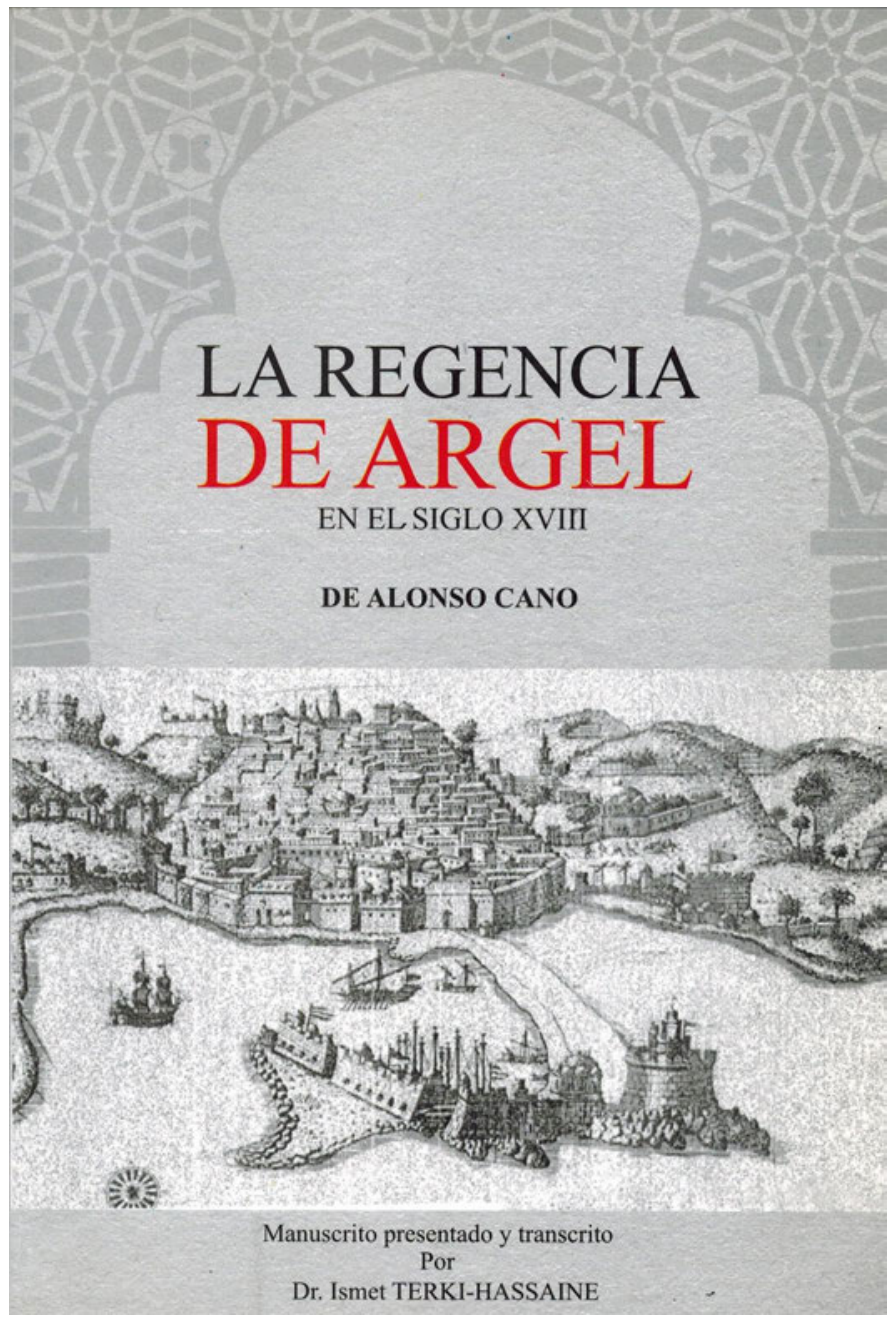



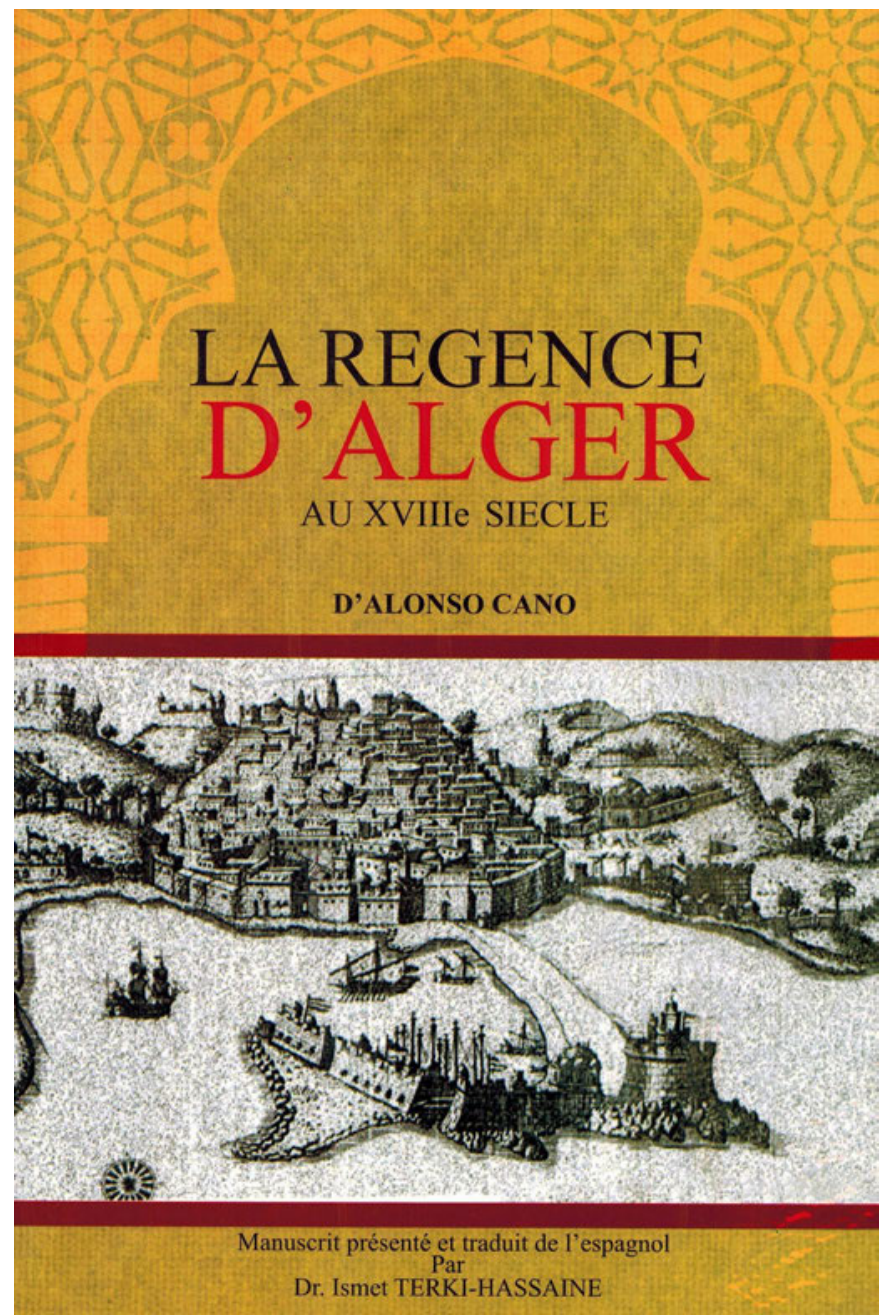


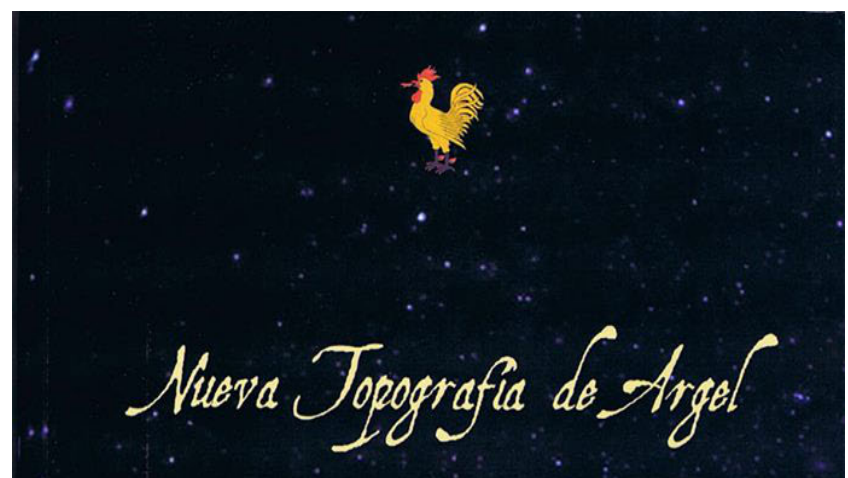

Fr. Alonso Cano y Nieto

Edición de Mireia Llopis Susierra,

Composición y Diseño Ana Enmicucx,

Estudio y Notas Andrés Díaz Borrás 